\title{
Project-Based Learning using Life Cycle Assessment Methodology in a Case Studio
}

\author{
José Alfredo Carazo Luna ${ }^{*} \quad$ Alejandra Velarde Galván ${ }^{2}$ \\ Moisés Manzano Herrera ${ }^{3} \quad$ Esmeralda Perez Cruz ${ }^{4}$ \\ 1.Universidad Tecnológica de la Mixteca, CP, 69000, Huajuapan de León, Oaxaca, México. Email: \\ alfredo@mixteco.utm.mx. \\ 2.Universidad Tecnológica de la Mixteca, CP, 69000, Huajuapan de León, Oaxaca, México. Email: \\ alevelar@mixteco.utm.mx. \\ 3.Universidad Tecnológica de la Mixteca, CP, 69000, Huajuapan de León, Oaxaca, México. Email: \\ mmanzano@mixteco.utm.mx. \\ 4.Industrial Engineering Student, Universidad Tecnológica de la Mixteca, CP, 69000, Huajuapan de León, \\ Oaxaca, México. Email: esme.perez.id@gmail.com. \\ * E-mail of the corresponding author: alfredo@mixteco.utm.mx
}

\begin{abstract}
.
The scientifically rigorous teaching strategies that the university-level teacher proposes in the classroom include tasks that lead the student to develop and apply an engineering methodology, and when it is put into practice, a benefit is obtained in society or in a community or population. Certain barriers have been detected for the engineering student to develop Project Based Learning (PBL) and be applied in real scenarios, in addition, little research can be found on the implementation of the PBL in engineering education. This leads to identifying areas of opportunity and generating new proposals for the application and integration of methodologies during the academic training of engineering students for the benefit of society. This document focuses on applying the Life Cycle Assessment (LCA) methodology in the final disposal phase in conjunction with Project Based Learning to a municipality in the Mixteca region. A general diagnosis of solid waste is carried out, to achieve this, a strategic plan is established in conjunction with the municipal authorities and an environmental awareness session among the population
\end{abstract}

Keywords: LCA, PBL, final disposal, strategic plan.

DOI: $10.7176 / \mathrm{JEP} / 11-33-03$

Publication date: November $30^{\text {th }} 2020$

\section{Introduction.}

The municipal authorities concerned with the well-being of society are committed to providing solutions and monitoring the different demands and needs, taking as a precedent that the completion of these pronouncements is often delayed due to a lack of financial resources designated by the State. Plan Estatal de Desarrollo Oaxaca 2016-2022 (2016). In the search for affordable proposals and concerned about the future benefits of a particular society, the authorities turn to higher-level educational centers such as universities in search of students with a profile and knowledge in the development and implementation of methodologies learned in the classroom, ideal for practice in real life supported by the teacher who has taught didactic techniques. The problem of environmental contamination of a place, region, community or municipality is one of the issues that are addressed in the classroom where students choose to implement a project that solves and reduces environmental impacts. The municipality of San Andrés Dinicuiti, in the state of Oaxaca, Mexico, is chosen because in that place live students who are studying industrial engineering and are concerned about bad practices in solid waste. The care of the environment as an alarming problem that does not distinguish places and in San Andrés Dinicuiti this problem is perceived by the lack of knowledge about the subject and the impacts that are generated day by day, wich have been increasing over the years with population growth. However the population has the custom of cleaning the community only on holidays, and it is precisely this activities that are carried out by custom that take them away from reality about the concepts and impacts that are generated and how is directly affect the environment. That is why this project focuses on identifying and solving through Project-Based Learning (PBL) and the Life Cycle Assessment (LCA), environmental problems in the municipality; from a series of meetings with the municipal authorities where the interest in reducing the impact on environment and rising social awareness through the development of an action and dissemination plan is rised. Flemming, S. (2000), SEDESOL(2016).

\section{Environment subjet.}

Educational programs for engineering students must comply with comprehensive training and once university studies are completed they may face different scenarios. One of the subjects covered is Environment, which provides the student with the development of competencies and skills that allow them to solve real situations in an environment threatened by the mismanagement of solid waste, industrial waste, discharges into rivers and seas, 
among others. The environment course is scheduled in the last semesters of the industrial engineering career. On this occasion, the students have the opportunity to identify a real scenario from which they come that contemplates some type of threat to the environment. With the teacher's help, strategies are developed, tools or methodologies seen in class are included and applied to solve the problem. In the first instance and if the student is allowed, there is an approach with the corresponding authorities of the municipality or municipal agency to which the student belongs. The professor of the subject prepares an official document that he delivers to the authorities to start the project. This research is carried out in San Andrés Dinicuiti, belonging to the municipality of Huajuapan de León, Oaxaca, Mexico. After receiving the theory on methodologies used to solve polluting scenarios, it is chosen to apply the Life Cycle Assessment (LCA) methodology in the "final disposition" phase. Pontalier, P, Sablayrolles, C. (2012)

\section{Project Based Learning.}

Project based learning can be defined briefly as a model that organizes learning around projects the identified a set of criteria to capture the uniqueness of PBL. This projects are central, not peripheral to the curriculum; and are focus on questions or problems that drive students to encounter and struggle with the central concepts and principles of a discipline. In terms of advantages of the PBL approach, learning by means of a project is likely to increase motivation, and give the students a sense of satisfaction, it is helpful for developing long-term learning skills, to develop deep, integrated understanding of content and process, it allows students learn to work together to solve problems, and it promotes responsibility and independent learning. PBL also contributes to bringing the classroom close to the profession through the acquisition of knowledge while solving practical and real cases closed to the professional world. In fact, PBL works to integrate and apply: (i) structured new knowledge covered in the course, (ii) knowledge learned in other courses, (iii) prior life experiential based knowledge, and (iv) new self-taught knowledge. The learning process focuses on self-directed study groups that discuss and analyze selected cases. The role of professors is mainly to facilitate the learning process; they assist students to understand the project problem, develop potential solutions, apply solutions to meet specifications and criteria, and when possible to construct new knowledge. Moreover, the assessment methods should be compatible with the learning process. Team work and assessment of team work are important issues related to project approaches. De los Rios, I. (2010), Aksela, M. (2019)

\section{Methodology.}

Environmental life-cycle assessment (LCA) provides a framework, an approach, and methods for identifying and evaluating environmental burdens associated with the life cycles of materials and services, from cradle-to-grave (or, as preferred by some, "cradle-to-cradle," which captures the recyclability of materials). Since the 1970s, there have been efforts to develop LCA methodology. In the 1990s, the Society of Environmental Toxicology and Chemistry (SETAC) in North America and the U.S. Environmental Protection Agency (USEPA) sponsored workshops and other projects designed to develop and promote consensus on a framework for conducting lifecycle inventory analysis and impact assessment. Similar efforts have been undertaken by SETAC in Europe, other international organizations (such as the International Standards Organization), and LCA practitioners worldwide. As a result of these efforts, consensus has been achieved on an overall LCA framework and a well-defined inventory methodology. Further, the art and science of impact assessment have been advanced by SETAC through publication of Life-Cycle Impact Assessment: The State-of-the-Art in North America and Toward a Methodology for Life-Cycle Impact Assessment in Europe. The goal definition element of an LCA identifies the purpose for the study and its intended application(s). This step will present reasons why the study is being conducted and how the results will be used. Scoping defines the boundaries, assumptions, and limitations of a particular LCA. It defines what activities and impacts are included or excluded and why. Scoping should be attempted before any LCA is conducted to ensure that:

- The breadth and depth of analysis are compatible with and sufficient to address the goal of the LCA.

- All boundaries, methodologies, data categories, and assumptions are clearly stated, comprehend sible, and visible. The goal-and-scope definition process is an integral part of any LCA study. At the outset of an LCA, before any data are collected, key decisions must be made regarding the scope and boundaries of the system being studied. These decisions are mainly determined by the goal, i.e., the defined reasons for conducting the study, its intended applications, and the target audience. Examples of generic goals and applications of LCA by public and private sector organizations include the following. Thorne, R. (2000), Astrup, A. (1997):

- Education and communication.

- Product design (design for the environment).

- Product development and improvement/R\&D.

- Pollution prevention.

- Assessment and reduction of potential liability.

- Strategic planning. 
- Assessing and improving environmental programs.

- Development of policy and regulations.

- Individual and organizational purchasing/procurement.

- Labeling.

- Developing market strategies.

- Environmental management systems/environmental performance evaluation.

For the purposes of this research, the following objectives are contemplated:

a) Education and communication. Because a team of high school students will be formed to support the community and the basic levels of education by preparing and disseminating information.

b) Pollution prevention. Intervention of the authorities, to modify and reduce bad practices in the final disposal of waste generated in the community.

c) Assessing and improving environmental programs. All states and municipalities comply with environmental legislation to avoid breaking the natural balance. It is important to generate environmental indicators that can be monitored and suggest improvements.

\subsection{Development of the Methodology}

To adapt the functionality of the LCA methodology, a work plan is formed that involves the following steps.

I. Commitments: A meeting is held with municipal authorities to expose the problem and how it should be blocked. A document is written describing the stages of the project. A group of young volunteers from the Instituto de Bachilleres del Estado de Oaxaca (IEBO) is invited to promote awareness in caring for the environment and the integration of an Ecological Network. Finally, a letter of commitment is signed, ensuring the tasks of each participant.

II. Information Gathering: Surveys are conducted in the San Andrés Dinicuiti community by volunteers, in order to obtain a diagnosis that allows identifying the information and knowledge of the inhabitants on the subject, actions that are practiced and impact on the environment and the antecedents of the municipal authorities in promoting the care of the environment. From the surveys, it is obtained that the majority of the population is unaware of the concept of the environment, few people separate the garbage and the perception of the municipal authorities in matters of development is not satisfactory. Expeditions are carried out to different places such as the Municipal garbage dump, rivers, school zones, among others to identify the hot spots of contamination in the area. Based on the information collected, the action plan is developed that addresses the most relevant and impactful problems.

III. Action and Dissemination: Based on the information collected, the action plan is developed that addresses the most relevant and impactful problems. When analyzing the information collected, it is identified that the most relevant problem is contamination by solid waste. The LCA methodology is then applied to identify the causative factors and the environmental impact. The LCA (Life Cycle Assessment) is the study of environmental aspects and potential impacts throughout the life cycle of a product, procedure or service. For the project, the study is focused on the last stage: "End of life", as shown below. Moro, C. (2013), ISO 14040 (2006)

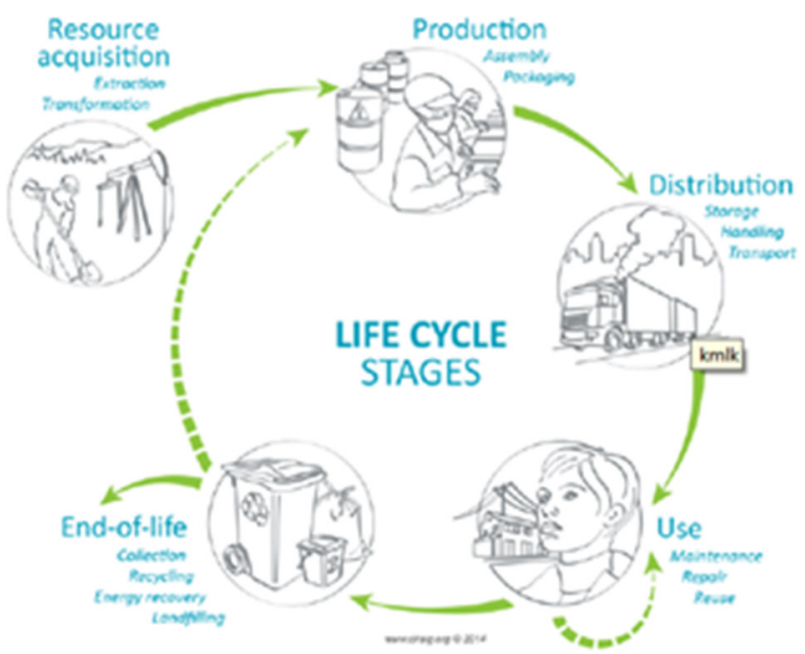

Figure 1. Representation of the Life Cycle Asessment.

An unofficial vehicle travels the main streets of the municipality and collects waste twice a week due to mismanagement. They are improperly transported, stored and incinerated with gasoline in an open-air landfill that is not properly structured. The municipal landfill is located on the highway. Due to the open-air conditions, the residues tend to spread polluting the natural landscapes and affecting nearby rivers and lands. In tourist and more 
frequented places in the community, unfavorable situations are observed, such as lack of maintenance.. These aforementioned factors gave rise to the planning and development of the action plan in conjunction with the municipal authorities. They agree to carry out cleaning actions on roads, tourist places and activities to promote caring for the environment.

The first action is to receive an orientation and training in the management of solid waste at the facilities of the Integral Center for Solid Waste (CITRESO) located in the city of Huajuapan de León, Oaxaca.

The second action is a meeting with the Municipal Commissioner to present the project to relocate the municipal garbage dump to reduce the environmental impact on the community. The economic resource for the new location of the municipal dump will be carried out at a later date.

In the third action, a cleaning cycle called "tequio" since ancient times is considered, in addition to promoting care for the environment. The "tequio" consists of a meeting with the inhabitants to develop cleaning activities and on this time volunteers and drivers of collective transport participate. The activities include raising awareness in caring for the environment and transmitting the message to different sectors of the population. Cleaning works are scheduled on the municipal road. They include ravines, tree pruning without affecting their growth, collection and separation of PET containers, glass containers, plastic bags, wrappers, material, hospital, debris, etc.

As a way of monitoring the last stage of the life cycle, the project also includes awareness activities and recycling of solid waste. Students of basic level of education participate and within the framework of the Christmas festivities, piñatas and Christmas decorations are made with recycled material such as leaves used in offices and schools, bags, cardboard, among others.

Finally, and to close the gap between the inhabitants and authorities of San Andrés Dinicuiti, a work agenda is established with well-defined activities, responsible for executing them, and schedules. In addition to creating a link with the next generations of society.

IV. Evaluation and monitoring: The activities that are constantly being carried out according to a program are cleaning rivers and natural environments as well as promoting respect for the environment in educational centers and the community in general.

Table 1. Scenarios before and after the project

\begin{tabular}{|l|l|}
\hline Before the project & After the project \\
\hline $\begin{array}{l}\text { There was no precedent of actions implemented that } \\
\text { helped protect the environment }\end{array}$ & $\begin{array}{l}\text { Currently there is a diagnosis of the community } \\
\text { situation, where the main problem of solid waste } \\
\text { contamination is identified. }\end{array}$ \\
$\begin{array}{l}\text { It is identified that most of the population is not } \\
\text { familiar with or is unaware of the concept of the } \\
\text { environment. }\end{array}$ & $\begin{array}{l}\text { There was no promotion by the municipal } \\
\text { authorities. }\end{array}$ \\
$\begin{array}{l}\text { The municipal authorities promoted the care of the } \\
\text { environment at all educational levels including } \\
\text { citizens. } \\
\text { Manual activities were promoted using recycled } \\
\text { material. } \\
\text { Social networks are used to show the progress of the } \\
\text { activities in the Municipal Council. }\end{array}$ \\
\hline $\begin{array}{l}\text { Frequent cleaning was not carried out in natural } \\
\text { areas. }\end{array}$ & $\begin{array}{l}\text { Cleaning activities were implemented in natural } \\
\text { areas frequented by the population and tourists such } \\
\text { as the "Pila", the "Triangulo" and the main road with } \\
\text { the support of the adults and youth of the } \\
\text { community. }\end{array}$ \\
\hline $\begin{array}{l}\text { There are no documents or plans to monitor the use } \\
\text { and disposal of waste as well as its impacts on the } \\
\text { community. }\end{array}$ & $\begin{array}{l}\text { The LCA methodology is applied in the End of Life } \\
\text { phase, in addition, training is received from } \\
\text { CITRESO to better manage solid waste. }\end{array}$ \\
\hline
\end{tabular}

\section{Evidence of the application of the LCA and PBL methodology}

Presentation to the municipal authorities of the strategy to develop the project. 

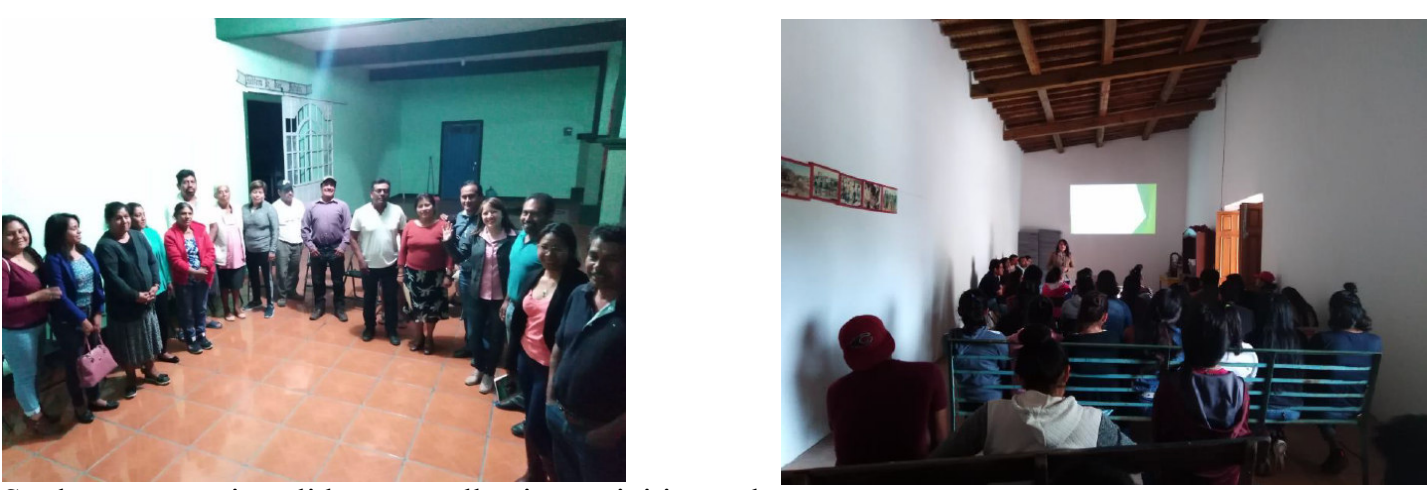

Student support in solid waste collection activities and awareness
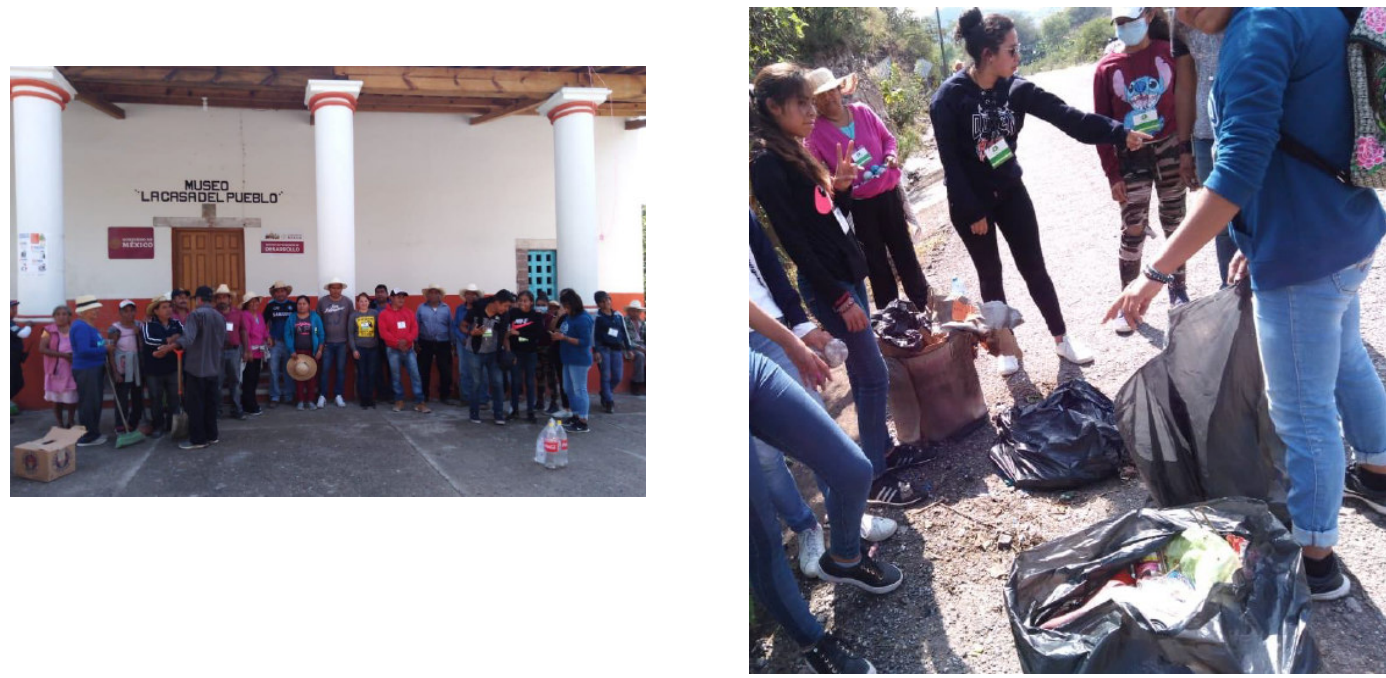

Use of waste and recycled material in Christmas season activities in the community
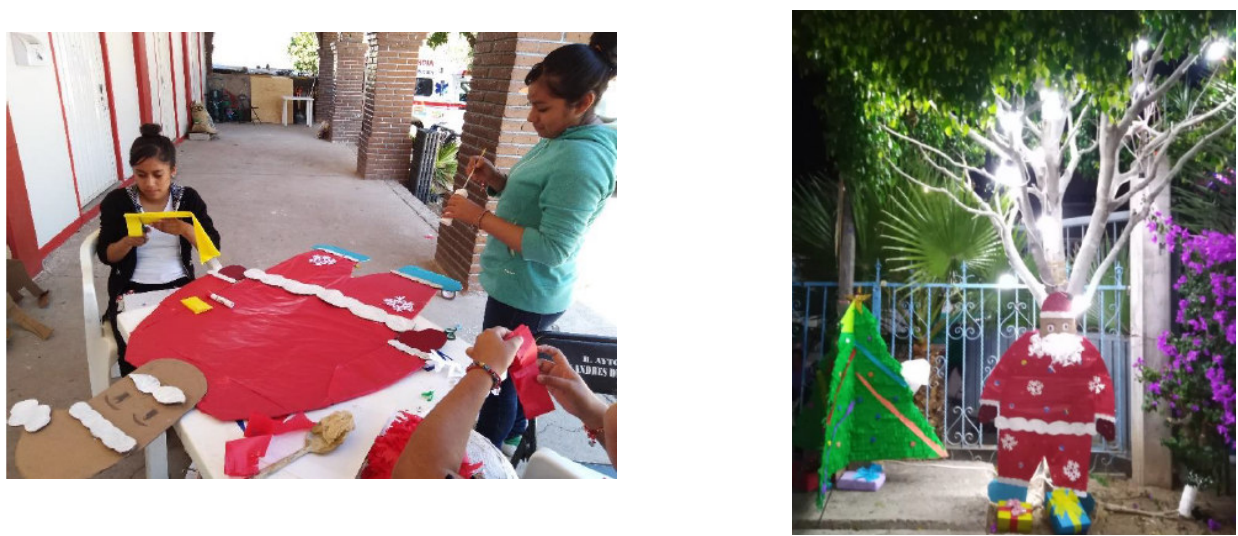

Participation and monitoring in cleaning and awareness work in tourist areas by the population. 

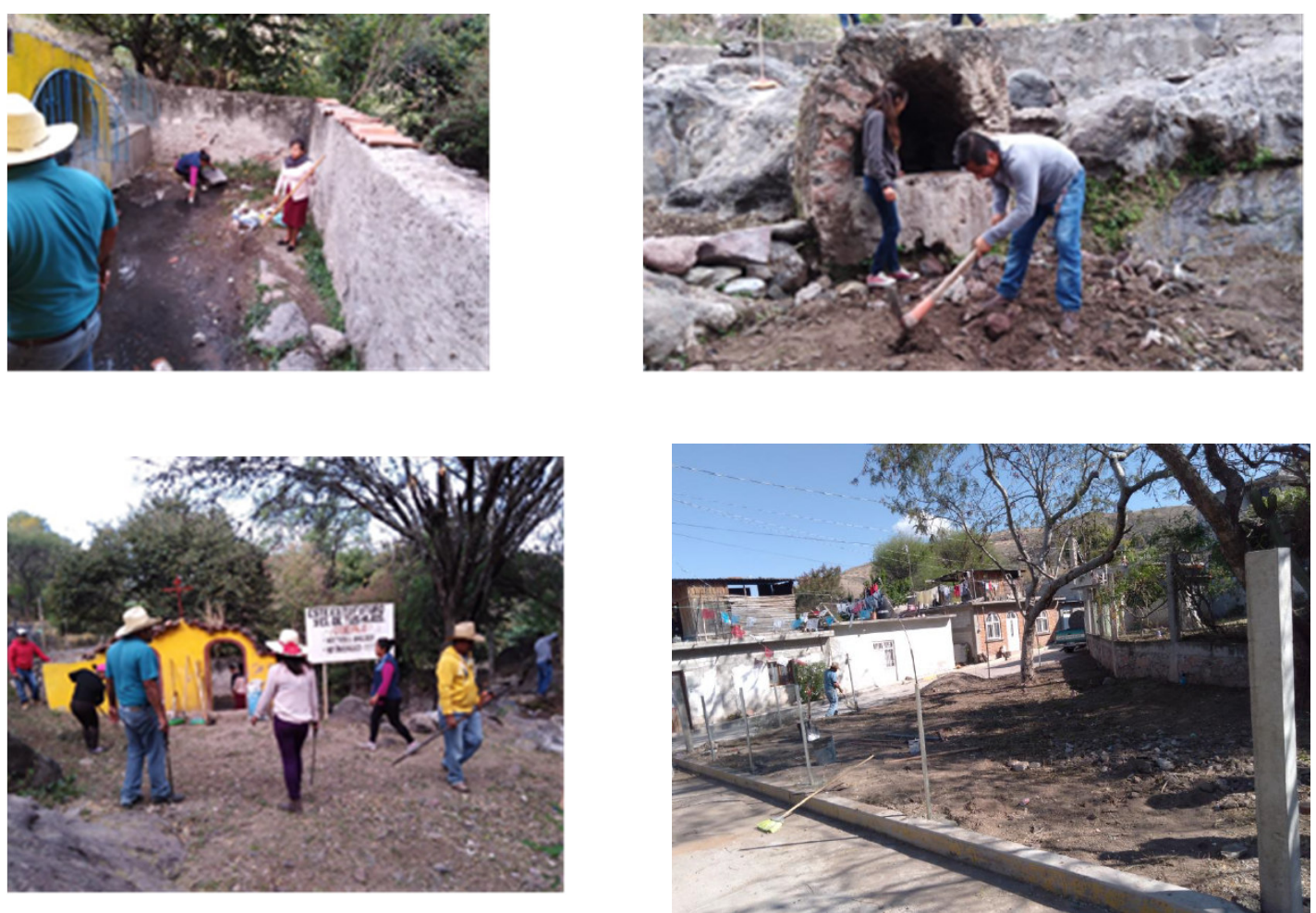

Presentation of results of the application of the LCA and PBL methodology with municipal authorities.

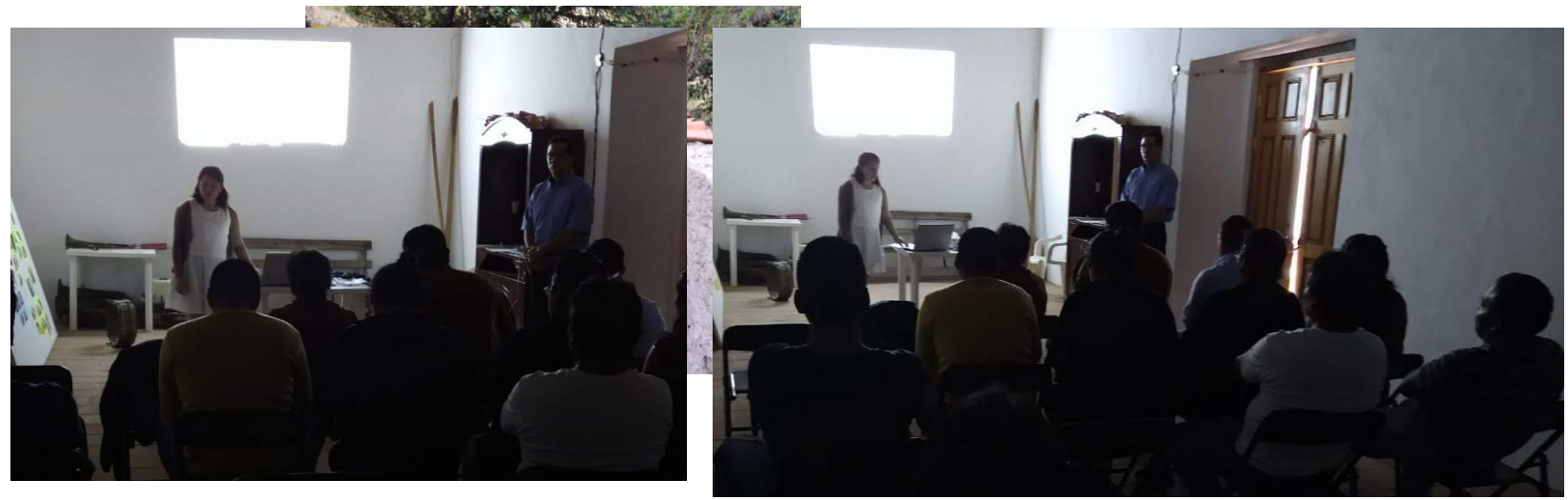

\section{Conclusions}

The student has identified how LCA has been one of the most interesting tools for environmental assessment. Its current wide use denotes that since its first application, the methodology appears to have evolved from a very specific tool for product assessment to a far ranging one, with an application to products, services, communities, environmental policies, processes, as a standalone tool or combined with other environmental assessment tools. Based on the results obtained, it is concluded that the proposed strategies and actions respond to the objective of the project, greatly reducing the impacts on the environment, significantly improving the natural environment and promoting in young people and children the commitment to preserve natural places and living spaces. It is proposed to continue with promotional activities to care for the environment and those that allow preserving natural areas, involving the population.

Project-based learning proves to be an ideal and current tool to address and face challenges in the daily life of future engineers of any career, university, individuals and groups of individuals. It encourages interdisciplinary work, allows developing ideas, analyzing needs and providing comprehensive solutions with practically no limitations. The student gains an overview in the real world and demonstrates improvements in their academic learning.

A future line of research is to strengthen in each school year the link between the University and society with the study of real cases so that students develop a project and apply engineering strategies. Which can mean expanding knowledge and solving everyday scenarios in the environment or in other areas to benefit a specific 
population.

\section{References}

Aksela, M., Haatainen, O. (2019), 'Project-Based Learning (PBL) in practise: active teachers' views of its' advantages and challenges, ResearchGate, 9-16.

Astrup, J., Hoffman, L., Mller, B., Schmidt, A. (1997), "Life Cycle Assessment. A guide to approaches, experiences and information sources. Environmental Issue Series. No.6, 1-104.

De los Rios, I., Cazorla, A., Díaz-Puente, J., Yagüe, J. (2010), "Project-based learning in engineering higher education: two decades of teaching competences in real environments". Procedia Social and Behavioral Sciences 2, Elsevier, 1368-1378.

Fleming, D. (2000), “A teacher's guide to Project-Based Learning”. AEL, ISBN-1-891677-08-X, 103p.

ISO 14040:2006 Environmetal management - Life cycle assessment - Principles and framework.

Moro, C., Mendes da Luz, L., Zocche, L., de Francico, A. (2013), “ Life Cycle Assessment as Entrepreneurial Tool for Business Management and Green Innovations. Journal of Technology Management \& Innovation, Volume 8, Issue 1, 44-53.

Pontailer, P. Sablayrolles, C. (2012) "Life cycle assessment (LCA) applied to the process industry: A review". The International Journal of Life cycle Assessment 1-23.

Plan Estatal de Desarrollo Oaxaca 2016 - 2022. Gobierno del Estado.

Thorne, R., Bouman, E., Guerreiro, C., Majchrzak, A. (2019), "Using life cycle assessment to inform municipal climate mitigation planning". Energy Policy 129, 173-181.

SEDESOL. (2016). San Andrés Dinicuiti, Oaxaca. Febrero 4,2020, de SEDESOL Sitio web: http://diariooficial.gob.mx/SEDESOL/2016/Oaxaca_089.pdf. 